\title{
Use of portable vitrectomy instrumentation (VISC X) in the rural Guatemalan highlands
}

\author{
JAMES D. KINGHAM, ${ }^{1}$ ROBERT H. POIRIER, ${ }^{2}$ SISTER MARY ANNEL, ${ }^{3}$ AND \\ SISTER DOROTHY ERICKSON ${ }^{3}$
}

From 'Sarasota, Florida, and ${ }^{2}$ San Antonio, Texas, USA, and ${ }^{3}$ Jacaltenango, Huehuetenango, Guatemala SUMMARY In a rural mountain setting 20 patients with blinding ocular opacities were treated surgically with modern vitrectomy techniques. There were no intraoperative or postoperative complications unique to the isolated environment. Because of its compact portability, the VISC X proved to be an ideal vitrectomy instrument. In addition to plastic lid procedures, cataract extraction, and strabismus surgery, repair of retinal detachment and vitrectomy in selected cases has been added to the armamentarium of surgeons who are seriously involved in exporting ophthalmology to remote places.

In 1978 we reported an improvised technique using liquid nitrogen for the treatment of retinal detachment in the rural Guatemalan Highlands.' In 1979 we returned to the Hospital Jacaltenango in Guatemala on a repeat medical and surgical expedition. This time we took a light-weight, portable, battery operated vitrectomy instrument $\left(\right.$ VISC X) ${ }^{2}$ in anticipation of selected cases in which it might be useful. In a period of 9 days we used the VISC $\mathrm{X}$ in the management of 20 cases which otherwise would have been inoperable or more difficult to manage (Table 1). We present here the indications and methods of vitrectomy instrument surgery which we found useful in the rural setting of ophthalmic care.

Table 1 Indications for vitrectomv instrument surgerv in Guatemala. 1979

\begin{tabular}{ll}
\hline Indication & Number of cases \\
\hline 1. Congenital cataract & 7 \\
2. Traumatic cataract & 3 \\
3. Secondary cataract & 5 \\
4. Vitreous haemorrhage and debris & 2 \\
5. Removal of extracapsular cataract remnants & 2 \\
6. Pupillary membrane & 1 \\
7. Management of vitreous loss in cataract surgery & 0 \\
8. Augmentation to retinal detachment surgery & 0 \\
\hline
\end{tabular}

Correspondence to James D. Kingham. MD. 1830 S. Osprey Avenue. Sarasota. Florida 33579. USA.

\section{Patients and methods}

The 20 patients were selected for surgery from approximately 600 outpatients seen during our 9 days in Jacaltenango. Patients arrived on foot, horseback, or were carried from as far as 100 kilometres for eye examination and treatment. All patients were, for the most part. Mayan Indians. The area from which they came is north-western Guatemala, and the primary geographic feature is steep volcanic mountains and sequestered valleys (Figs. 1, 2). In some areas trachoma and tuberculosis are endemic. Malnutrition is ubiquitous.

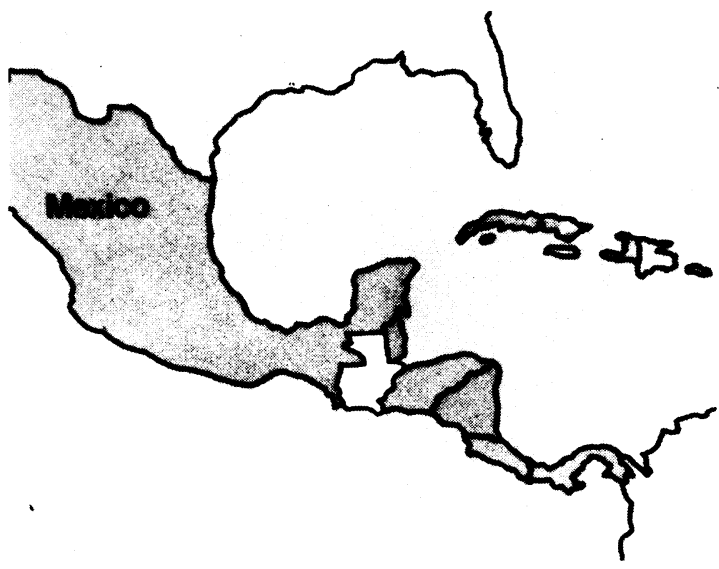

Fig. 1 Guatemala is the first country in Central America south of Mexico. 


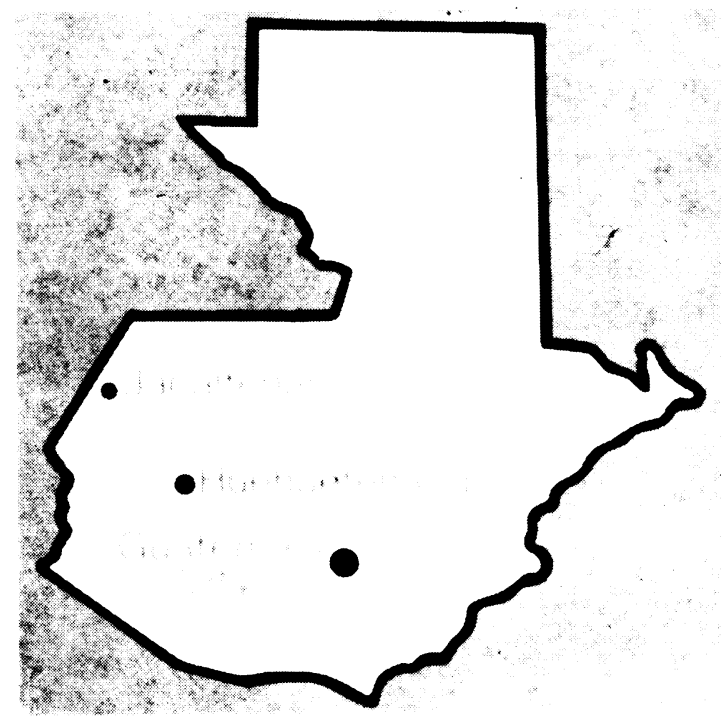

Fig. 2 Jacaltenango in north-western Guatemala is $346 \mathrm{~km}$ up the Pan American Highwav from Guatemala City and across 2 mountain ranges.

All operations were done in a small hospital operating room under aseptic and sterile conditions. Local anaesthesia was used in all cases. Most cases were done under observation with the Codman portable operating microscope, but one pars plana vitrectomy was done under visualisation with the indirect ophthalmoscope. Balanced salt solution or Ringer's lactate solution was used as infusion.

All operations were performed by a surgeon experienced in retinal and vitreous surgery (J.D.K.) or corneal and external surgery (R.H.P.). All operations were done through a small incision at the corneoscleral limbus with the exception of 2 cases done through the pars plana. The surgical technique was straightforward and standardised and has been previously described using such various vitrectomy instrumentation as the Machemer-Parel VISC. ${ }^{3}$ Douvas Rotoextractor, ${ }^{4}$ and Peyman vitrophage. ${ }^{56}$

The following case reports are representative of the types of surgery which were performed.

\section{Case reports}

Cases 1 and 2. Congenital cataract and removal of extracapsular cataract extraction remnants. A 23-yearold man had bilateral congenital cataracts which had become progressively worse since early childhood. He had no nystagmus. Vision was light perception in both eyes. He had a planned extra-capsular cataract extraction in his right eye which resulted in excessive residual cortical material in the anterior chamber. On the second postoperative day the cortical material was removed with the VISC. One day later the dense cataract was removed from his left eye with the VISC. The next day the media were clear in both eyes, with a good red reflex. With aphakic correction subjective vision had improved dramatically in both eyes.

Case 3. Traumatic cataract. A 27-year-old man had been kicked in the face by an ox 4 years previously, with a resultant dense traumatic cataract in his left eve. An agricultural worker, he was considered an excellent candidate for a planned extracapsular cataract extraction by VISC technique, primarily for return of full visual field. The lens was removed with the VISC leaving an intact posterior capsule. Postoperatively, without aphakic correction, subjective vision and visual field were improved.

Case 4. Secondary cataract. A 43-year-old widow, long afflicted with tuberculosis, lived an isolated life in a small hut with 2 children. She had a blind phthisical right eye and only light perception in her left eye. The left pupil was miotic and secluded and there was a dense cataract. Corneal keratic precipitates and hypotony suggested an inflammatory aetiology for the secondary cataract. A tuberculous aetiology was postulated for the uveitis. The lens was removed with the VISC through a limbal incision after synechiolysis. The posterior capsule was left intact. Five days postoperatively vision had improved to hand movements.

Case 5. Pupillarv membrane. A 62-year-old man had unplanned extracapsular cataract surgery 12 years previously with subsequent dense pupillary membrane and updrawn pupil in his right eye. Vision was light perception. A mature cataract was present in his left eye. Two days after uneventful and successful intracapsular cataract extraction in his left eye the pupillary membrane in the right eye was excised with the VISC. With aphakic correction subjective vision was improved dramatically in both eyes on the second postoperative day.

Case 6. Vitreous haemorrhage. A 26-year-old man had dense vitreous haemorrhage in his right eye. The left eye showed perivascular sheathing and intraretinal haemorrhages. Vision was hand movements in the right eye and 20/25 in the left eye. The diagnosis was periphlebitis retinae (Eales's disease). A pars plana vitrectomy was done with the VISC under observation with the indirect ophthalmoscope, with adequate clearing of a central core of blood. Postoperatively he had diffuse blood in the vitreous cavity, which was expected to clear. Subjective vision was slightly better than before operation.

Case 7. Vitreous debris and cyst from uveitis. A 33-year-old man had vision of $20 / 40$ in his right eye and counting fingers at 6 feet $(1.8 \mathrm{~m})$ in his left eye. The left eye had diffuse vitreous debris with a large 
mobile spherical lesion about 6 disc diameters in size. A pars plana vitrectomy was done under observation with the operating microscope. The spherical lesion similar to the intra-vitreous cysticercus described by Hutton et al. ${ }^{7}$ was removed with ease along with the cloudy vitreous. An iatrogenic posterior retinal tear was treated with injection of air and drainage of subretinal fluid. Postoperatively we could not determine the status of the retina at the time we left.

\section{Results}

All patients who underwent surgery with the VISC X experienced subjective visual improvement except an 11-year-old boy with secondary cataract who postoperatively was found to have a retinal detachment (an attempt was made to repair the retinal detachment) and the above mentioned patient (case 7) who developed an iatrogenic retinal detachment. One additional patient was found after lensectomy to have a retinal detachment, which was successfully repaired. In most patients subjective vision was expected to continue to improve.

Quantitative postoperative visual acuity was difficult to assess, as the duration of field activity was limited to 2 weeks. However, follow-up care was continued through paramedical personnel and by the mission medical doctors (M.A. and D.E.). The use of graphic quiz games has proved mostly unsuccessful for us in assessing either preoperative or postoperative vision in the illiterate Guatemalan Indians, prompting us to evaluate the Arden grating test in future field work.

\section{Discussion}

Cataract surgery, enucleation, and lid surgery are commonly performed in remote rural areas. ${ }^{89}$ Recognising retinal detachment as a complication of cataract surgery in $2-3 \%$ of cases, ${ }^{10}$ we improvised a method while in Guatemala of treating retinal detachments with cotton tip sponges dipped in liquid nitrogen for cryosurgical adhesion. ${ }^{\prime}$ Encouraged by our initial success we decided to increase our surgical capabilities by taking a portable vitrectomy instrument. To our surprise we found more patients than we had expected in whom surgery with the VISC would be beneficial, or in some cases absolutely necessary.

We believe cataract removal with the VISC produced superior results than had we done standard extracapsular cataract extractions in traumatic or secondary cataracts, especially in young patients. The extracapsular removal of congenital cataracts was facilitated by the VISC, and in no case did we encounter vitreous loss or difficulty removing residual cortex, as had been our experience previously. Clearly, vitreous haemorrhage cannot be cleared by any other surgical treatment. Removal of pupillary membranes by the VISC is a well documented procedure, " and indeed in our hands is the method of choice. Furthermore the 2 patients who were found to have previously undiagnosed retinal detachments were benefited, after lensectomy, by having subsequent retinal reattachment surgery. In these cases the operative site was secure and there was little concern over wound dehiscence as would have been the case in standard large-wound extracapsular techniques.

Although we did not use the VISC to remove anterior vitreous associated with vitreous loss at cataract extraction, this certainly would be an added indication, as well as the use of pars plana vitrectomy to augment the management of vitreous traction in difficult cases of retinal detachment. ${ }^{12}$

The vitrectomy instrument chosen for this expedition, the VISC $\mathrm{X}$, suited our purposes admirably. It is compact and battery operated, can be autoclaved, is easily portable in its packing box with dimensions of $38 \times 63 \times 71 \mathrm{~cm}(15 \times 25 \times 38$ inches $)$, and light weight, with a total packed weight of $15 \mathrm{~kg}$ (33 pounds).

We believe that our experience with the VISC $X$ in a remote rural setting adds another dimension to the overall clinical capabilities of visiting ophthalmic field teams and underscores the practicality of the concept of 'exporting ophthalmology'. ${ }^{13}$ It is now possible to transport light weight microscopes and vitrectomy instrumentation to remote areas that have no access to ophthalmic surgery. We would like to emphasise that this is difficult and exacting microsurgery under the best of conditions. Needless to say, conditions in remote rural areas are much less than ideal, and surgery such as this should be undertaken only by those surgeons who are experienced in the technique of retinal and vitreous surgery and who are prepared and qualified to deal with real and potential complications.

\section{References}

I Kingham JD. Poirier RH. Wolters RH. Annel M. Retinal reattachment surgery in the remote Guatemalan Highlands. Ophthalmic Surg 1978: 9: 67-9.

2 Parel JM. Machemer R. Aumayr W. A new concept for vitreous surgery. IV: Improvements in instrumentation and illumination. Am J Ophthalmol 1974: 77: 6-12.

3 Machemer R. Vitrectomv: A Pars Plana Approach. New York: Grune and Stratton. 1975.

4 Douvas NG. The cataract roto-extractor (a preliminary report). Trans Am Acad Ophthalmol Otolaryngol 1973; 96: 792-800.

5 Diamond HG. Kaplan HJ. Lensectomy and vitrectomy for complicated cataract secondary to uveitis. Arch Ophthalmol 1978: 96: 1798-804. 
6 Pevman GA. Raichand M. Goldberg MF. Surgery of congenital and juvenile cataracts: a pars plicata approach with the vitrophage. Br J Ophthalmol 1978: 62: 780-3.

7 Hutton EL. Vaiser A. Synder WB. Pars plana vitrectomy for removal of intravitreous cysticercus. Am J Ophthalmol 1976: 81: 571-3.

8 Whitfield R Jr. Eve surgery in rural Kenva. Ophthalmic Surg 1973: 4: 46-52.

9 Kiu HS. McGannon WJ. Tolentino F et al. Massive cataract relief in eve camps. Ann Ophthalmol 1977: 9: 503-8.
10 Scheie HG. Morse PH. Incidence of retinal detachment following cataract extraction. Arch Ophthalmol 1973; 89: 293-5.

11 Treister G. Machemer R. Pars plana approach for pupillary membranes. Arch Ophthalmol 1978; 96: 1014-6.

12 Machemer R. Allen AW. Retinal tears 180 degrees and greater. Management with vitrectomv and intravitreal gas. Arch Ophthalmol 1976: 94: 134()-6.

13 Allen HF. Exporting ophthalmology. Arch Ophthalmol 1966: 76: 1-2. 